\title{
Nurse perceptions of organizational culture and its association with the culture of error reporting: a case of public sector hospitals in Pakistan
}

\author{
Sara Rizvi Jafree ${ }^{1}$, Rubeena Zakar ${ }^{2}$, Muhammad Zakria Zakar ${ }^{3}$ and Florian Fischer ${ }^{4^{*}}$
}

\begin{abstract}
Background: There is an absence of formal error tracking systems in public sector hospitals of Pakistan and also a lack of literature concerning error reporting culture in the health care sector. Nurse practitioners have front-line knowledge and rich exposure about both the organizational culture and error sharing in hospital settings. The aim of this paper was to investigate the association between organizational culture and the culture of error reporting, as perceived by nurses.

Methods: The authors used the "Practice Environment Scale-Nurse Work Index Revised" to measure the six dimensions of organizational culture. Seven questions were used from the "Survey to Solicit Information about the Culture of Reporting" to measure error reporting culture in the region. Overall, 309 nurses participated in the survey, including female nurses from all designations such as supervisors, instructors, ward-heads, staff nurses and student nurses. We used SPSS 17.0 to perform a factor analysis. Furthermore, descriptive statistics, mean scores and multivariable logistic regression were used for the analysis.
\end{abstract}

Results: Three areas were ranked unfavorably by nurse respondents, including: (i) the error reporting culture, (ii) staffing and resource adequacy, and (iii) nurse foundations for quality of care. Multivariable regression results revealed that all six categories of organizational culture, including: (1) nurse manager ability, leadership and support, (2) nurse participation in hospital affairs, (3) nurse participation in governance, (4) nurse foundations of quality care, (5) nurse-coworkers relations, and (6) nurse staffing and resource adequacy, were positively associated with higher odds of error reporting culture. In addition, it was found that married nurses and nurses on permanent contract were more likely to report errors at the workplace.

Conclusion: Public healthcare services of Pakistan can be improved through the promotion of an error reporting culture, reducing staffing and resource shortages and the development of nursing care plans.

Keywords: Organizational culture, Error reporting, Pakistan, Nurse, Public sector

\section{Background}

Although confirmed statistics are missing, evidence from developed countries estimates that billions of dollars are wasted in the health care system annually due to underreporting of errors [1]. In the absence of formal error tracking systems, especially for the developing world, the successful maintenance of a voluntary error reporting

\footnotetext{
*Correspondence: f.fischer@uni-bielefeld.de

${ }^{4}$ Department of Public Health Medicine, School of Public Health, Bielefeld

University, P.O. Box 10013133501 Bielefeld, Germany

Full list of author information is available at the end of the article
}

culture gains increased importance to ensure patient safety [2]. A favorable error reporting culture is known to be positively associated with a positive organizational culture [3]. The organizational culture in a hospital setting is the product of shared values, attitudes and patterns of behavior which medical practitioners observe during the process of care delivery [4].

Nurse practitioners are more competent in and likely to report errors, compared to other health care providers [5]. Favorable organizational cultures for nurse practitioners have been described as ones with satisfactory coworker 
communication, higher levels of nurse autonomy, efficient nursing care plans and adequacy in staffing and resources [6, 7]. When nurses and other medical practitioners are facilitated with a positive organizational culture, their commitment to a culture of error reporting and error sharing increases, consequently improving patient safety and reducing mortality rates $[8,9]$. WHO also indicates that the organizational culture of a hospital influences health practitioner job satisfaction, role delivery and quality of patient care [10].

More than $95 \%$ of nurses in Pakistan are females [11]. However, nurses are in extreme shortage in the region. The nurse to doctor ratio is at 1:3 and the nurse to patient ratio at 1:50,000 [11]. Nurse problems related to recruitment and retention in the region have been found to be linked to a complex combination of organizational culture issues, including: (i) unsatisfactory coworker relations [12], (ii) the inferior status of the nurse profession and inadequate compensation and benefits [13, 14], (iii) negative nurse identity and high rates of violence against nurses $[15,16]$, and (iv) the absence of nursing care plans and autonomous work participation [17]. The Health Ministry and the Punjab Healthcare Commission are the official government regulatory bodies that have authority to improve the quality of health care service provision and clinical governance in Pakistan. However, budget allocations and policies for patient safety are neglected areas in the health care organizations of the country [18]. There is no formal error tracking system in public sector hospitals of the region and no formal laws exist to penalize offending practitioners [19]. The curriculum inclusion and monitoring of medical and nursing code of ethics is officiated by the Pakistan Medical and Dental Council (PMDC) and Pakistan Nursing Council (PNC). However, compulsory curriculum inclusion of medical ethics, examination of clinical ethics and formal monitoring of clinical ethics practice is not carried out [20]. Additionally, the status of error reporting from the perspective of public sector nurses in Pakistan has not yet been addressed by research.

\section{Study objective and relevance of this study}

The aim of this paper was to investigate the association between the organizational culture and the culture of error reporting in the public health care sector, as perceived by nurses. It is agreed that policy improvements in the public sector health care services are possible only when there is adequate empirical research about the status quo [21]. Therefore, the findings of this study will attempt to map a plan for improved organizational culture for nurses, and, consequently, facilitate to improve error reporting and patient safety. The study results are expected to be relevant not only for nurses and other medical practitioners working in the public sector, but also for the private health care sector. Our hypotheses for the study were: (1) When organizational culture is favorable, the error reporting culture will be favorable, and (2) When each of the six subscales of organizational culture are favorable (1. nurse manager ability, leadership and support, 2. nurse participation in hospital affairs, 3. nurse participation in governance, 4 . nurse foundations of quality care, 5. nurse coworker communication, 6. nurse staff and resource adequacy), the error reporting culture will also be favorable.

\section{Methods}

This study is part of a doctoral dissertation entitled "Nurses' perceptions of organizational culture and its association with error reporting: A study of tertiarycare public sector hospitals in Lahore", conducted by the first author of this paper. The study used a descriptive and correlational design, using cross-sectional data and mixed methodology. The qualitative parts of this study have been published earlier [22, 23].

\section{Setting and sampling procedure}

The study was performed in the city of Lahore, which is the capital of the Punjab province in Pakistan. Lahore is the second largest city of Pakistan and the second highest populated city of the country. It is estimated to have more than ten million inhabitants. Data from the website of Pakistan Institute of Medical Sciences official website was used to conveniently sample two geographically spaced tertiary care public sector hospitals from Lahore, out of a total of nine [24]. The two sampled hospitals have been named Hospital A and Hospital B. Both hospitals have high patient turnovers and large inpatient capacities, and are catering to a different set of patients from the rural and urban Lahore District and also from the surrounding villages of Lahore City. Combined, the two hospitals have a large daily out-patient turnover rate of more than 3,800 patients and an inpatient capacity of approximately 1,890 beds.

All registered female nurses who had been working in the hospital for more than one year were sampled. Each designation was sampled, including nurse supervisors, nurse ward heads, nurse instructors, staff nurses and nurse students. Registered nurse students were included in the sample, because they actively perform clinical duties after the first three months of their enrollment as students, and thus they also have rich experience about the state of organizational culture and error reporting in the hospital setting. In Hospital A there is 1 nurse supervisor, 650 staff nurses, 150 nurse ward heads, 20 nurse instructors, and 415 nurse students. In Hospital B (Sheikh Zayed hospital) there is 1 nurse supervisor, 600 staff nurses, 100 nurse ward heads, 13 nurse instructors, and 320 nurse students. Both hospitals combined have a 
total of 2,270 nurses, with 2 nurse supervisors, 250 nurse ward heads, 33 nurse instructors, 1,250 staff nurses, and 735 nurse students. Yamane's formulae [25] was used to determine a sample size from an estimated female Punjab nurse workforce of 11,065 . Surveys were distributed to the different nurse designations according to their respective weightage. In this way, $35 \%$ of each nurse designation was sampled, including both nurses supervisors, 440 staff nurses, 90 nurse ward heads, 12 nurse instructors, and 260 nurse students.

\section{Instruments}

Survey questions and guidelines were conducted and written in the English language, which is the official academic and working language of the country. Two standardized instruments were used including the "Practice Environment Scale-Nurse Work Index Revised" (PES-NWI) [26], and the "Survey to Solicit Information about the Culture of Reporting" (SSICR) [27]. The validity and reliability of both the PES-NWI $[28,29]$ and the SSICR $[30,31]$ has been established by previous research in health care policy improvements. Respondents were provided, through an extensive literature review, with a summarized list of errors that may occur during health care service delivery by medical practitioners (Table 9 in Appendix) [32-34]. A pretest of the questionnaire was conducted with 35 nurse respondents to ascertain any loopholes that could be rectified before the final administration.

Section I of the questionnaire contained 18 questions pertaining to the socio-demographic characteristics of nurses. These questions include age ('20-29 years', '30-39 years' and '40+ years'), marital status ('Never married,' 'Currently married' and 'Divorced/separated/ widowed'), regional belonging ('Punjab,' 'Sindh', 'Baluchistan' and 'Khyber Pakhtun Khwan'), religion ('Muslim,',Christian', 'Hindu' and 'Ahmedi'), total number of children ('None', ' $1-2$ children' and ' 3 or more children'), total monthly income (PKR '5,000-19,999', '20,000-39,999' and ' $\geq 40,000$ '), place of residence ('college hostel', 'hospital resident colony' and 'private home'), highest nursing degree ('Nursing Diploma, 'BSc Nursing' and 'MSc Nursing'), current designation ('Nurse supervisor,' 'Nurse instructor', 'Nurse ward head, 'Staff nurse' and 'Student nurse'), type of labor contract ('Permanent' and 'Contractual'), employment status ('Full-time' and 'Part-time'), current government grade ('16 grade' and '17 grade'), additional employment in private sector ('Yes' and 'No'), and additional hours worked at the public sector hospital during the night, day or evening ('Yes' and 'No').

Section II contained 31 questions from the PES-NWI, which measures the organizational culture of a hospital by a composite score which is aggregated to the unit level [26]. Items on the scale consist of 5 subscales which measure different aspects of organizational culture, including: (1) nurse manager ability, leadership and support (5 items), (2) nurse participation in hospital affairs (7 items), (3) nurse participation in governance (2 items), (4) nurse foundations of quality care (10 items), (5) nurse-coworkers relations (3 items), and (6) nurse staffing and resource adequacy (4 items).

Section III contained seven questions from the SSICR. The questions measure the culture of error reporting in a hospital and indicate how comfortable the respondent is in sharing errors at the workplace with supervisors and coworkers.

Both the scales have a 4 point rating scale, which indicate respondent extent of agreement with each item. The response categories include: 1 = strongly agree, 2 = agree, 3 = disagree, $4=$ strongly disagree. The instrument is scored by calculating mean subscale scores and a total composite score for each respondent which can range from 1-4. Higher scores indicate a less favorable organizational culture and culture of error reporting. Two of the seven items from the error reporting variables had to be reverse coded so that the scoring was aligned across all items of the tool. Reliability analysis was conducted for both the PES-NWI and the SSICR to confirm Cronbach's alphas of scales. A Cronbach's alpha of above 0.7 is considered a reliable measure for health and social science research [35]. For this study, the overall internal consistency ranged satisfactorily between values of 0.743 to 0.881 .

\section{Data collection}

The questionnaire was distributed at the two hospitals in the time period from November 2013 to January 2014. All nurse employees are required to sign an attendance register daily, placed in the offices of their respective nurse ward head, before the start of their shift. Hence all nurse designations visited the nurse ward head office daily at the start of three different shifts of either 08:00 am, 02:00 pm or 08:00 pm. It was deemed suitable to communicate with nurses at this place of contact to recruit interested participants. Nurses were asked to read the cover letter attached to the survey and select a time to complete the survey in a reserved room of the nursing school of each respective hospital. Surveys were filled in nursing school class rooms, specifically reserved for data collection, with 15-30 nurses at a time. The classrooms afforded privacy and a comfortable setting, away from the hospital building, clinical wards, patients and attendants, work pressures, male coworkers and other work-related intrusions. The survey completion time fell between 20-35 min. The first author was present to answer questions related to the survey. Respondents sealed their completed surveys and dropped them in a box before leaving the nursing school. Both the nurse supervisors from each hospital were sampled, 440 surveys were distributed to staff nurses, 90 to nurse ward heads, 12 to nurse instructors and 260 to nurse students 
(Table 1). In total, 804 questionnaires were distributed, but only 309 nurses pre-booked a time to complete the survey in reserved rooms. All 309 nurses completed the survey and were included in the final analysis (response rate: $34.8 \%)$.

\section{Data analysis}

Raw data was first entered into Excel. It was then transferred into SPSS 17.0 for analysis. A significance level of 0.05 was assigned for all statistical analyses. First, a factor analysis was used to reduce data and confirm subscales of relevance for the study. Factor analysis was deemed suitable to validate the NESPWI for Pakistani public sector hospitals [36-38], as this tool, to the best of researchers' knowledge, has not been used in the region before. Principal component analysis (PCA) was used with varimax rotation, as guided by previous research $[26,39,40]$. The following conditions for PCA were met: (i) sample size of above 50 cases, (ii) normal distribution, and (iii) all the variables of organizational culture correlating with each other above 0.2 and no correlations of above 0.9 (avoiding fears of multicollinearity).

Descriptive statistics are provided to show sociodemographic and employment characteristics of nurse respondents. Composite scores for subscales of organizational culture and error reporting were calculated [41-45]. Mean scores were also calculated ranging from 1-4 for subscales of organizational culture, composite organizational culture and error reporting. As recommended by literature, scores under the values of 2.5 were considered favorable and scores of above the value of 2.5 were considered unfavorable. Simple bivariate logistic regression and multivariable logistic regression models were used [46-49] to check for the association between: (i) organizational culture and its subscales with error reporting, and (ii) nurse socio-demographic characteristics and error reporting. The aim was to identify the odds of a favorable error reporting culture when organizational culture and its subscales are favorable, and also to identify the odds of a favorable error reporting culture in relation to the socio-demographic features of the nurse. The enter method was used. Variables were recoded into bivariate categories in order to use logistic regression. Organizational culture and its six subscales were recoded with dummy variables of $0=$ unfavorable organizational culture and 1 = favorable organizational culture. Error reporting was recoded with a dummy variable of $0=$ unfavorable error reporting culture and $1=$ favorable error reporting culture. The significance of the main effects was estimated by computing the confidence level for Exp (B) and was presented in form of odds ratios (OR), with accompanying $95 \%$ confidence intervals $(95 \% \mathrm{CI})$. Each of the variables of organizational culture, its subscales and the socio-demographic characteristics of nurses were adjusted for nurse age (as a continuous variable), nurse literacy and nurse monthly income.

\section{Ethical permission, reliability and validity}

Ethics committee permission was obtained from the Institutional Review Board, University of the Punjab, and also from the hospitals and nursing institutes where data collection took place. The ethics of the research process for this study were observed diligently, especially in consideration of sampling working women in developing regions, with the absence of structural and legal support [50]. All participants were informed and assured by attaching a cover letter to the questionnaire, describing the objectives of the research and ensuring confidentiality and anonymity. Informed consent was taken from the participants. Private rooms were requested in nursing schools where all surveys were filled and respondents were able to complete the survey in privacy and also to ask any questions related to the survey. Face and

Table 1 Nurse samples from Hospital A and Hospital B

\begin{tabular}{|c|c|c|c|c|c|c|}
\hline Hospital & Nurse supervisors & Staff nurses & Nurse ward heads & Nurse instructors & Students & Total \\
\hline \multicolumn{7}{|l|}{ Hospital A } \\
\hline Actual headcount & 1 & 650 & 150 & 20 & 415 & 1,236 \\
\hline Target sample & 1 & 220 & 45 & 6 & 130 & 402 \\
\hline Response & 1 & 126 & 28 & 5 & 42 & 202 \\
\hline \multicolumn{7}{|l|}{ Hospital B } \\
\hline Actual headcount & 1 & 600 & 100 & 13 & 320 & 1,034 \\
\hline Target sample & 1 & 220 & 45 & 6 & 130 & 402 \\
\hline Response & 1 & 79 & 12 & 6 & 9 & 107 \\
\hline \multicolumn{7}{|l|}{ Hospitals combined } \\
\hline Total actual headcount & 2 & 1,250 & 250 & 33 & 735 & 2,270 \\
\hline Total target sample & 2 & 440 & 90 & 12 & 260 & 804 \\
\hline Total response & 2 & 205 & 40 & 11 & 51 & 309 \\
\hline
\end{tabular}


content validity of the questionnaire was confirmed through consultation and discussion with senior researchers, nurse supervisors and nurse ward heads. Cronbach's alpha was used to check the internal consistency and reliability of the items in the instrument [51, 52]. Internal validity was ensured by using a simple random sample so that each participant had an equal chance of selection. Construct validity was assured by using PCA.

\section{Results}

\section{Factor analysis}

The Kaiser-Meyer Olkin test and the Bartlett test were both satisfactory and supportive to conducting a factor analysis. Six factors were extracted by PCA, including all the six subscales for organizational culture represented in the PES-NWI. Results showed $70.8 \%$ of the variance of the construct being studied (i.e. organizational culture). Communalities were extracted (Table 2), and each item

Table 2 Factor loadings and communalities from PCA with varimax rotation for organizational culture

Component

Commun-alities

Nurse Participation in Governance

Q19. Staff nurses are involved in the internal governance of the hospital

Q26. Staff nurses have the opportunity to serve on hospital and nursing department committees

Nurse Manager Ability Leadership and Support

Q21. An administration who listens to and responds to employee concerns

Q22. A director of nursing highly visible and accessible to staff

Q25. Nursing administrators consult with staff on daily problems and procedures

Q27. A nursing supervisor equal in power and authority to other top level hospital executives

Q38. A head nurse who is a good manager and leader

Q39. A head nurse/supervisor who backs up the nursing staff in decision making, even if the conflict is with a physician .690

Q40. Supervisors use mistakes as learning opportunities, not criticism 534

Q41. A supervisory staff that is supportive of the nurses

Q42. Praise and recognition for a job well done

Nurse Participation in Hospital Affairs

Q20. Many opportunities for advancement of nursing personnel

Q23. Opportunity for staff nurses to participate in policy decisions

Q24. Career development/clinical ladder opportunity

Nurse Foundations for Quality of Care

Q28. Use of nursing diagnoses

Q29. An active quality assurance program

Q30. An orientation program for newly hired RNs

Q31. Nursing care is based on a nursing, rather than a medical, model

Q32. Patient care assignments that foster continuity of care

Q33. A clear philosophy of nursing that pervades the patient care environment

Q34. Written, up-to-date nursing care plans for all patients

Q35. High standards of nursing care are expected by the administration

Nurse coworker relations

Q43. A lot of teamwork between nurses and doctors

Q44. Physicians and nurses have good relationships

Q45. Functional collaboration (joint practice) between nurses and physicians

Q46. Enough staff to get the work done

Q26. Staff nurses have the opportunity to serve on hospital and nursing department committees

Nursing Staffing and Resource

Q47. Enough registered nurses to provide quality patient care 
explains at least $50 \%$ of the variance of the study construct.

\section{Mean scores of scales}

The nurse respondents average composite mean score for organizational culture was ranked favorably at 2.38 $(\mathrm{SD}=0.616)$. The following three areas were ranked unfavorably by nurses (Table 3): (i) error reporting culture (Mean score $=2.62$; $\mathrm{SD}=0.500$ ), (ii) staffing and resource adequacy (Mean score $=2.56$; $\mathrm{SD}=0.901$ ), and (iii) nurse foundations for quality of care (Mean score $=2.59$; $\mathrm{SD}=$ 0.630). The following subscales of organizational culture have been ranked favorably by nurse respondents: (i) nurse participation in hospital affairs (Mean score $=2.34$; $\mathrm{SD}=0.726$ ), (ii) nurse participation in governance (Mean score $=2.33$; $\mathrm{SD}=0.781$ ), and (iii) nurse-coworkers relations (Mean score $=2.26$; $\mathrm{SD}=0.704$ ).

\section{Socio-demographic characteristics of the sample} Of the 309 respondents (Table 4), 202 were from Hospital A (65.4\%) and 107 were from Hospital B $(34.6 \%)$. About half of the nurse respondents was in the age group of $20-29$ years $(n=161,52.1 \%), 87$ belonged to the age group of 30-39 years (28.2\%) and $19.7 \%(n=61)$ were 40 years of age and above. The average age was 30.5 years $(\mathrm{SD}=9.85)$. The majority was currently married ( $n=173,55.9 \%$ ); 130 respondents $(42.1 \%)$ were unmarried and 6 respondents $(1.9 \%)$ were divorced, widowed or separated. Nearly all respondents belonged to the province of Punjab ( $n=301,97.4 \%), 6$ were from Sindh (1.9\%) and one each $(0.3 \%)$ was from Baluchistan and Khyber Pakhtun Khwan, respectively. Most of the nurse respondents were Muslims ( $n=231,74.7 \%), 76$ were Christians $(24.6 \%)$ and one respondent each $(0.3 \%)$ was Hindu and Ahmedi. More than half of the respondents $(n=157$, $50.8 \%)$ had no children, 63 had one or two children $(20.4 \%)$ and 89 had three children or more (28.8\%). A total of 56 nurses earned between PKR 5,000-19,999 (18.1 \%), 154 nurses earned between PKR 20,000-39,999
(49.8\%) and 99 nurses earned more than PKR 40,000 (32.0\%). The average income per month of the nurses in the sample was PKR 33,754. With regard to the place of residence, the majority $(n=212,68.6 \%)$ of nurse respondents lived in private accommodations, 53 (17.2\%) of nurse students lived in college hostel and 44 (14.2\%) lived in the hospital residence colony.

A total of 174 (56.3 \%) nurses had a highest nursing degree of diploma (Table 5), 120 (38.8 \%) had earned a BSc in Nursing and 15 (4.8\%) had an MSc in Nursing. Majority of the nurses $(n=205,66.3 \%)$ had a designation of staff nurse, 51 were student nurses $(16.5 \%), 40$ nurses were ward heads (12.9\%), 11 were nurse instructors $(4.2 \%)$ and two were nurse supervisors $(0.6 \%)$. A little more than half of the nurse respondents had a permanent position $(n=176,57.0 \%)$. Nearly all the nurse respondents were full-time employees $(n=94.8 \%)$. Most of the nurse respondents belonged to the 16 grade government scale $(n=256$, $82.8 \%) .73 .8 \%(n=228)$ of the nurses were not working at a private clinic after duty hours at the hospital, whereas $81(26.2 \%)$ were working at a private clinic. A total of 59 nurses reported having to work additional hours as night duty (19.1\%), 128 reported having to work additional hours in the day $(41.4 \%)$ and 124 had to work additional hours in the evening (40.1\%).

\section{Bivariate analysis}

Composite scores for organizational culture, the six subscales of organizational culture and error reporting were calculated (Table 6). The normality assumption was evaluated and scores of all subscales of organizational culture followed the normal distribution. The correlations, using Pearson correlation, between all study variables significantly correlated with values of above 0.3. Correlation coefficients also showed that the variables have a positive relationship and move together in a linear fashion.

Table 3 Mean scores for organizational culture and error reporting scales and organizational culture subscales (score ranges from 1 to 4$)$

\begin{tabular}{lcc}
\hline Scale & Mean score & Standard deviation \\
\hline Error reporting & 2.620 & .500 \\
Organizational culture & 2.384 & .616 \\
Nurse participation in governance & 2.338 & .781 \\
Nurse participation in hospital affairs & 2.348 & .726 \\
Nurse manager ability, leadership and support & 2.296 & .632 \\
Nurse foundations for quality care & 2.599 & .630 \\
Nurse staffing and resource adequacy & 2.562 & .902 \\
Nurse coworker relations & 2.261 & .705 \\
\hline
\end{tabular}


Table 4 Socio-demographic characteristics $(n=309)$

\begin{tabular}{|c|c|c|c|}
\hline Socio-demographic variables & Unfavorableerror reporting $n(\%)^{*}$ & Favorable error reporting $n(\%)^{*}$ & $n(\%)$ \\
\hline \multicolumn{4}{|l|}{ Tertiary care public sector hospital } \\
\hline Hospital A & $107(53.0)$ & $95(47.0)$ & $202(65.4)$ \\
\hline Hospital B & $24(22.4)$ & $83(77.6)$ & $107(34.6)$ \\
\hline \multicolumn{4}{|l|}{ Age } \\
\hline 20-29 years & $28(17.4)$ & $133(82.6)$ & $161(52.1)$ \\
\hline 30-39 years & $68(78.2)$ & $19(21.8)$ & $87(28.2)$ \\
\hline $40+$ years & $35(57.4)$ & $26(42.6)$ & $61(19.7)$ \\
\hline \multicolumn{4}{|l|}{ Marital status } \\
\hline Never married & $26(20.0)$ & $104(80.0)$ & $130(42.1)$ \\
\hline Currently married & $102(59.0)$ & $71(41.0)$ & $173(55.9)$ \\
\hline Divorced/ separated/ widowed & $3(50.0)$ & $3(50.0)$ & $6(1.9)$ \\
\hline \multicolumn{4}{|l|}{ Region } \\
\hline Punjab & $128(42.5)$ & $173(57.5)$ & $301(97.4)$ \\
\hline Sindh & $2(33.3)$ & $4(66.7)$ & $6(1.9)$ \\
\hline Baluchistan & $1(100)$ & - & $1(0.3)$ \\
\hline Khyber Pakhtun Khwan & - & $1(100)$ & $1(0.3)$ \\
\hline \multicolumn{4}{|l|}{ Religion } \\
\hline Muslim & $83(35.9)$ & $148(64.1)$ & $231(74.7)$ \\
\hline Christian & $47(62.7)$ & $28(37.3)$ & $76(24.6)$ \\
\hline Hindu & $1(100)$ & - & $1(0.3)$ \\
\hline Ahmedi & - & $1(100)$ & $1(0.3)$ \\
\hline \multicolumn{4}{|l|}{ Children } \\
\hline None & $30(19.1)$ & $127(80.9)$ & $157(50.8)$ \\
\hline $1-2$ & $36(57.1)$ & $27(42.9)$ & $63(20.4)$ \\
\hline $3+$ & $65(73.0)$ & $24(27.0)$ & $89(28.8)$ \\
\hline \multicolumn{4}{|l|}{ Income (in PKR) } \\
\hline $5,000-19,999$ & $10(18.9)$ & $43(81.1)$ & $56(18.1)$ \\
\hline 20,000-39,999 & $69(44.8)$ & $85(55.2)$ & $154(49.8)$ \\
\hline$\geq 40,000$ & $50(50.5)$ & $49(49.5)$ & $99(32.0)$ \\
\hline \multicolumn{4}{|l|}{ Home residency } \\
\hline College hostel & $16(30.2)$ & $37(69.8)$ & $53(17.2)$ \\
\hline Hospital resident colony & $18(40.9)$ & $26(59.1)$ & $44(14.2)$ \\
\hline Private home & $97(46.6)$ & $111(53.4)$ & $212(68.6)$ \\
\hline
\end{tabular}

*Frequencies for each subscale add up to the number of participants in the study

\section{Simple bivariate logistic regression}

The contingency results for regression have been shown in Table 7. Results for bivariate logistic regression (Table 8) show that the composite organizational culture variable and the subscales of organizational culture all have high odd ratios with favorable culture of error reporting. When organizational culture is favorable, nurses perceived higher odds of error reporting (OR: 2.43, 95 \% CI: 1.51-3.92). When nurse participation in governance (OR: 1.83, $95 \%$ CI: 1.16-2.87) and nurse participation in hospital affairs (OR: 2.96, 95 \% CI: 1.85-4.70) are favorable, there is a higher odds of error reporting. Similarly, when nurse manager ability, leadership and support (OR: 1.56, 95 \% CI: 0.98-2.48), nurse foundations for quality of care (OR: 3.12, $95 \%$ CI: 1.96-4.98), nurse staffing and resource adequacy (OR: 7.83, 95 \% CI: 4.64-13.22) and nurse-coworker relations (OR: 6.13, 95 \% CI: 3.62-10.37) were favorable, the odds of error reporting was high. The results also show that nurses above the age of 30 years had extremely higher odds of reporting errors (OR: 13.73, 95 \% CI: 7.91-23.86). Married nurses (OR: 5.54, 95 \% CI: 3.39-9.05) and nurses earning an income of above PKR 40,000 (OR: 2.55, $95 \%$ 
Table 5 Nurse employment characteristics $(n=309)$

\begin{tabular}{|c|c|c|c|}
\hline Employee variables & Unfavorableerror reporting $n(\%)^{*}$ & Favorable error reporting $n(\%)^{*}$ & $n(\%)$ \\
\hline \multicolumn{4}{|l|}{ Highest degree attained } \\
\hline Nursing diploma & $72(41.4)$ & $102(58.6)$ & $174(56.3)$ \\
\hline BSc in Nursing & $56(46.7)$ & $64(53.3)$ & $120(38.8)$ \\
\hline MSc in Nursing & $3(20.0)$ & $12(80.0)$ & $15(4.8)$ \\
\hline \multicolumn{4}{|l|}{ Current nurse designation } \\
\hline Supervisor & - & $2(100)$ & $2(0.6)$ \\
\hline Student (+1 year clinical staff) & $10(19.6)$ & $41(80.4)$ & $51(16.5)$ \\
\hline Staff nurse & $93(45.4)$ & $112(54.6)$ & $205(66.3)$ \\
\hline Ward head & $22(55.0)$ & $18(45.0)$ & $40(12.9)$ \\
\hline Nurse instructor & $6(46.2)$ & $7(53.8)$ & $11(3.6)$ \\
\hline \multicolumn{4}{|l|}{ Labor contract } \\
\hline Permanent & $106(60.2)$ & $70(39.8)$ & $176(57.0)$ \\
\hline Contractual & $25(18.8)$ & $108(81.2)$ & $133(43.0)$ \\
\hline \multicolumn{4}{|l|}{ Employment status } \\
\hline Full-time & $128(43.7)$ & $165(56.3)$ & $293(94.8)$ \\
\hline Part-time & $3(18.8)$ & $13(81.3)$ & $16(5.2)$ \\
\hline \multicolumn{4}{|l|}{ Government grade } \\
\hline 16 grade & $106(42.6)$ & $143(57.4)$ & $256(82.8)$ \\
\hline 17 grade & $21(39.6)$ & $32(60.4)$ & $53(17.2)$ \\
\hline \multicolumn{4}{|l|}{ Private job } \\
\hline Yes & $55(67.9)$ & $26(32.1)$ & $81(26.2)$ \\
\hline No & $76(33.3)$ & $152(66.7)$ & $228(73.8)$ \\
\hline \multicolumn{4}{|l|}{ Additional night duty } \\
\hline Yes & $27(45.8)$ & $32(54.2 \%)$ & $59(19.1 \%)$ \\
\hline No & $104(41.6)$ & $146(58.4 \%)$ & $250(80.9 \%)$ \\
\hline \multicolumn{4}{|l|}{ Additional day duty } \\
\hline Yes & $86(67.2)$ & $42(32.8)$ & $128(41.4)$ \\
\hline No & $45(24.9)$ & $136(75.1)$ & $181(58.6)$ \\
\hline \multicolumn{4}{|l|}{ Additional evening duty } \\
\hline Yes & $84(67.7)$ & $40(32.3)$ & $124(40.1)$ \\
\hline No & $47(25.4)$ & $138(74.6)$ & $185(59.9)$ \\
\hline
\end{tabular}

*Frequencies for each subscale add up to the number of participants in the study

CI: 1.54-4.21) had higher odds of reporting errors. Also, nurses on a permanent contract (OR: 6.98, $95 \%$ CI: 4.21-11.57) were more likely to report errors.

\section{Multivariable logistic regression}

Multivariable logistic regression was performed to calculate the adjusted odds ratio (AOR), holding income, education and age (as a continuous variable) as constants (Table 8). Results were highly significant for the odds ratios between error reporting and organizational culture and its subscales. When organizational culture (AOR: 3.58, 95 \% CI: 1.93-6.63), nurse participation in governance (AOR: 3.33, 95 \% CI: 1.87-5.95), nurse participation in hospital affairs (AOR: 5.08, 95 \% CI: 2.69-9.57), nurse manager ability, leadership and support (AOR: 2.61, 95 \% CI: 1.40-4.84), nurse foundations of quality of care (AOR: 4.83, $95 \% \mathrm{CI}$ : 2.59-9.02), nurse staffing and resource adequacy (AOR: 7.86, 95 \% CI: 4.18-14.75) and nurse coworker relations (AOR: 5.58, 95 \% CI: 2.97-10.50) were all favorable, the odds of error reporting were significantly higher. Also, married nurses (AOR: 1.33, $95 \% \mathrm{CI}: 0.17-0.63$ ) and nurses with a permanent contract (AOR: 1.29, $95 \%$ CI: 0.14-0.599) had higher odds of reporting errors.

\section{Discussion}

The results of this study are consistent with expectations that organizational culture and the culture of error reporting are positively associated. 
Table 6 Pearson's correlation matrix for organizational culture subscales and error reporting

\begin{tabular}{llllllll}
\hline Variables & ER & Governance & NPHA & NMALS & NFQC & NSRA & NCR \\
\hline ER & 1.000 & & & & & & \\
Governance & $.310^{*}$ & 1.000 & & & & & \\
NPHA & $.406^{*}$ & $.712^{*}$ & 1.000 & & & & \\
NMALS & $.324^{*}$ & $.808^{*}$ & $.752^{*}$ & 1.000 & & & \\
NFQC & $.350^{*}$ & $.740^{*}$ & $.743^{*}$ & $.811^{*}$ & 1.000 & & \\
NSRA & $.630^{*}$ & $.591^{*}$ & $.715^{*}$ & $.676^{*}$ & $.614^{*}$ & 1.000 & \\
NCR & $.634^{*}$ & $.472^{*}$ & $.582^{*}$ & $.557^{*}$ & $.509^{*}$ & $.710^{*}$ & 1.000
\end{tabular}

Notes: ER Error reporting, NPHA Nurse participation in hospital affairs, NMALS Nurse manager ability, leadership and support, NFQC Nurse foundations for quality care, NSRA Nurse staffing and resource adequacy, NCR Nurse coworker relations

${ }^{*} p<0.01$

\section{Mean score results}

Our sample respondents ranked the error reporting culture in their hospitals as unfavorable. This has significant implications for other public sector hospitals in the region, since previous research confirms that no formal error tracking systems exist in the Pakistan healthcare setup and also that education in ethics observance and administrative policy measures for promotion of ethical cultures are absent [53]. Currently, there are no allencompassing state medical laws in the country for the safeguard of either patients or medical and nurse practitioners. There may be several reasons for the absence of an error reporting culture in the hospital settings of Pakistan, as perceived by female nurses in this study.

Table 7 Contingency table showing the relationship between organizational culture, its subscales and error reporting $(n=309)$

\begin{tabular}{lll}
\hline $\begin{array}{l}\text { Organizational culture } \\
\text { and its subscales }\end{array}$ & $\begin{array}{l}\text { Unfavorable error } \\
\text { reportingn (\%)* }\end{array}$ & $\begin{array}{l}\text { Favorable error } \\
\text { reportingn (\%)* }\end{array}$ \\
\hline Favorable organizational culture & $36(22.9)$ & $121(77.1)$ \\
Unfavorable organizational culture & $95(62.5)$ & $57(37.5)$ \\
Favorable NPG & $40(27.2)$ & $107(72.8)$ \\
Unfavorable NPG & $91(56.2)$ & $71(43.8)$ \\
Favorable NPHA & $37(25.0)$ & $111(75.0)$ \\
Unfavorable NPHA & $94(58.4)$ & $67(41.6)$ \\
Favorable NMALS & $58(30.9)$ & $130(69.1)$ \\
Unfavorable NMALS & $73(60.3)$ & $48(39.7)$ \\
Favorable NFQC & $31(22.6)$ & $106(77.4)$ \\
Unfavorable NFQC & $100(58.1)$ & $72(41.9)$ \\
Favorable NSRA & $40(21.1)$ & $150(78.9)$ \\
Unfavorable NSRA & $91(76.5)$ & $28(23.5)$ \\
Favorable NCR & $25(17.0)$ & $122(83.0)$ \\
Unfavorable NCR & $106(65.4)$ & $56(34.6)$
\end{tabular}

*Frequencies for each subscale add up to the number of participants in the study
First, senior doctors and physicians have an elevated status and elite labels, which supports bullying and blameshifting in the hospital setting against junior medical practitioners and nurses [54]. Second, the healthcare sector of the region has a blame culture with punitive action taken against individuals, which prevents individuals from error sharing [55]. Third, nursing is a feminized profession in the region, with female nurses reluctant to report errors due to male dominated and patriarchal work environments and the fear of having to face workplace violence and retribution [19].

Study results also show that hospital staffing and resource adequacy is perceived by nurse respondents as unsatisfactory. Severe shortages in resources and staffing in the public sector hospitals of Pakistan critically undermine efforts of medical practitioners to ensure patient safety [14]. Other research from the region confirms that corruption in the health care sector, with public sector hospitals commonly devoid of basic and life-saving medicines and medical equipment, is responsible for both shortages and high rates of mortality [56]. Of the total national gross domestic product, only $2.9 \%$ is spent on health care and only $1.2 \%$ is allocated to the public sector [57]. Although more than $70 \%$ of the service provision in health care is provided by the private sector in the region, it is estimated that $74 \%$ of the population of Pakistan avail public health care services due to lack of funds [57]. In addition, public sector staffing is lacking due to inadequate budget allocations for hiring and compensation of medical and nurse practitioners. This has led to low enrollment and high rates of immigration [58].

The nurse professional is an integral member of the health care sector who is responsible directly for patient safety, the efficiency of the health care organization and the overall wellbeing of the population [59]. The results of this study, however, highlight that nurse foundations for quality of care in the hospital administration are ranked as unfavorable by respondents. Other research also suggests that Pakistani hospitals are dominated by medical care plans, with little attention to nursing care plans [60]. This may be because nursing is a feminized profession in the region, and male dominated medial administrations give minimal emphasis to nursing care plans for patient care delivery and instead give prominence to medical care plans [61]. Nursing is perceived in patriarchal regions as a care provision, restricted to cleaning, washing and execution of orders passed by doctors and physicians [62]. Nonnurse medical practitioners, medical administrators and patients do not recognize that nurses have medical training and are aware of patient's medical needs. In this way nursing care plans are not given precedence.

An unexpected finding was that nurses scored other subscales of organizational culture, such as nurse participation in governance, nurse participation in hospital 
Table 8 Simple bivariate logistic regression and multivariable regression for predictors of higher error reporting $(n=309)$

\begin{tabular}{|c|c|c|c|c|}
\hline Variables & OR for higher error reporting $(95 \% \mathrm{Cl})$ & $p$-value & AOR for higher error reporting $(95 \% \mathrm{Cl})$ & $p$-value \\
\hline \multicolumn{5}{|l|}{ Organizational culture } \\
\hline Favorable organizational culture & $2.43(1.51-3.92)$ & $<0.001$ & $3.58(1.93-6.63)$ & $<0.001$ \\
\hline Unfavorable organizational culture & 1 & & 1 & \\
\hline \multicolumn{5}{|l|}{ Nurse participation in governance } \\
\hline Favorable NPG & $1.83(1.16-2.87)$ & 0.009 & $3.33(1.87-5.95)$ & $<0.001$ \\
\hline Unfavorable NPG & 1 & & 1 & \\
\hline \multicolumn{5}{|l|}{ Nurse participation in hospital affairs } \\
\hline Favorable NPHA & $2.96(1.85-4.70)$ & $<0.001$ & $5.08(2.69-9.57)$ & $<0.001$ \\
\hline Unfavorable NPHA & 1 & & 1 & \\
\hline \multicolumn{5}{|c|}{ Nurse manager ability, leadership and support } \\
\hline Favorable NMALS & $1.56(0.98-2.48)$ & 0.057 & $2.61(1.40-4.84)$ & $<0.001$ \\
\hline Unfavorable NMALS & 1 & & 1 & \\
\hline \multicolumn{5}{|l|}{ Nurse foundations for quality care } \\
\hline Favorable NFQC & $3.12(1.96-4.98)$ & $<0.001$ & $4.83(2.59-9.02)$ & $<0.001$ \\
\hline Unfavorable NFQC & 1 & & 1 & \\
\hline \multicolumn{5}{|l|}{ Nurse staffing and resource adequacy } \\
\hline Favorable NSRA & $7.83(4.64-13.22)$ & $<0.001$ & $7.86(4.18-14.75)$ & $<0.001$ \\
\hline Unfavorable NSRA & 1 & & 1 & \\
\hline \multicolumn{5}{|l|}{ Nurse coworker relations } \\
\hline Favorable NCR & $6.13(3.62-10.37)$ & $<0.001$ & $5.58(2.97-10.50)$ & $<0.001$ \\
\hline Unfavorable NCR & 1 & & 1 & \\
\hline \multicolumn{5}{|l|}{ Age } \\
\hline$\geq 30$ years & $13.73(7.91-23.86)$ & $<0.001$ & & \\
\hline$\leq 29$ years & 1 & & & \\
\hline \multicolumn{5}{|l|}{ Marital status } \\
\hline Married & $5.54(3.39-9.05)$ & $<0.001$ & $1.33(1.17-1.64)$ & 0.001 \\
\hline Not married & 1 & & 1 & \\
\hline \multicolumn{5}{|l|}{ Income } \\
\hline$\geq 40,000$ PKR & $2.55(1.54-4.21)$ & $<0.001$ & & \\
\hline$\leq 39,999$ PKR & 1 & & & \\
\hline \multicolumn{5}{|l|}{ Degree } \\
\hline BSc in Nursing or above & $1.68(1.07-2.65)$ & 0.025 & & \\
\hline Diploma & 1 & & & \\
\hline \multicolumn{5}{|l|}{ Designation } \\
\hline Manager or instructor & $2.15(1.15-4.02)$ & 0.017 & & \\
\hline Staff or student nurse & 1 & & & \\
\hline \multicolumn{5}{|l|}{ Nature of employment contract } \\
\hline Permanent & $6.98(4.21-11.57)$ & $<0.001$ & $1.29(1.14-1.60)$ & 0.001 \\
\hline Contractual & 1 & & 1 & \\
\hline
\end{tabular}

Notes: NPG Nurse participation in governance, NPHA Nurse participation in hospital affairs, NMALS Nurse manager ability, leadership and support, NFQC Nurse foundations for quality care, NSRA Nurse staffing and resource adequacy, NCR Nurse coworker relations

affairs, nurse manger ability, leadership and support, and nurse coworker relations as favorable. Previous studies in the region indicated that nurse autonomy, participation in hospital policy-making and teamwork are extremely unfavorable $[12-14,17]$. It may be that nurse perceptions of favorable organizational culture are highly dependent on nurse education, training and exposure. For example, nurses in the sample may not be 
comparing their work environment to hospitals in developing nations. They could be strongly influenced by cultures in their wider community. Their perception of the organizational culture at their workplace may be better than their domestic and home environments [63]. There is also the disadvantage of attempting to collect survey data about sensitive topics in blame cultures and patriarchal communities, which may influence female respondents in indicating anything negative about governance and management.

\section{Regression results}

This study furthermore confirms, through multivariable regression results, that for an improved error reporting culture, organizational culture and all its six categories (nurse manager ability, leadership and support, nurse participation in hospital affairs, nurse participation in governance, nurse foundations of quality care, nursecoworkers relations, and nurse staffing and resource adequacy) need to be favorable. Regression results support findings from other international research $[43,64,65]$. Also, our findings show that error reporting is more common amongst nurses who are married and on a permanent contract. Other studies show that married nurses are more likely to participate in studies about errors [66], and this may be because married women are more secure in facing the consequences of error reporting, like blame, shame, retribution and job loss, due to the safety of a dual-income earning household. Furthermore, nurses on permanent contract may be more likely to report errors because of the difficulty in having their state contracts or jobs rescinded, due to extremely slow bureaucratic processing by the government [56].

\section{Limitations}

There are several limitations of this study. The size of the sample is relatively small and excludes public sector tertiary care hospitals across other cities and rural areas of Pakistan. The low response rate of $34.8 \%$ was due to the lack of time available of busy nurses and also the unwillingness of nurses to participate in what was considered a sensitive topic in a male-dominated work organization. In addition, the responses of nurses are guided by their perceptions, which are influenced by their level of education, on-going training and exposure to magnet hospitals. Also, because of the small sample, findings cannot be generalized. Despite the limitations, this study has significant strengths. It is the only research from Pakistan assessing the relationships between nurse perceptions of organizational culture and the culture of error reporting in public sector hospitals. We hope that our study's findings will have wider macro implications, as improved patient safety is known to help improve overall public health and reduce health costs for the national economy. Additionally, the findings highlight the critical shortages in staffing and resources and the inadequacy of nursing care plans for patient safety culture in the healthcare sector of the region.

\section{Conclusion and policy recommendations}

Findings from our study indicate that a favorable organizational culture, and each of its six components, is important to encourage a favorable culture of error reporting. Our study identifies three main areas that need improvement, including an increase in staffing and resources, developing nursing care plans and improving the error reporting culture. The installation of mandatory and independently monitored error reporting systems, for developing economies like Pakistan, is a process that requires time, fund allocation and structural changes. In such circumstances the voluntary error reporting between coworkers and management and subordinate assumes significance. There is need for independent monitoring of organizational culture and error reporting culture to encourage honest and reliable feedback from healthcare practitioners and nurses.

Nurses, and other health care practitioners must make efforts through union mobilization and gender solidarity, in order to improve (i) their professional status and the development of formal nursing care plans, and (ii) budget allocations for staffing and resource adequacy in the hospital setting [22]. It is also recommended that the nursing profession is propped with overtly manifest networks and facilities in the hospital settings (e.g. separate nursing offices, nurse front-desk enclosures, nurse trays and even nurse assistant wardboys who define the hierarchy) to emphasize the importance of the nursing care plans [67].

It will be important to invest time and resources in the training of health care employee culture towards a more progressive non-blame culture and encourage a culture of error reporting between coworkers. This may be done through regular and combined training sessions for doctors, physicians and nurses [68]. Apart from the inclusion of error reporting in the code of ethics, and in formal curricula, monitoring and accountability bodies within the public sector healthcare organizations must be established to oversee error sharing and error reporting without individual penalization. It is also recommended that the medical, dental and nursing councils (PMDC and PNC) hold monthly court sessions to protect and defend whistleblowers who are actively reporting errors and getting penalized for it by coworkers. This will also help to improve error reporting in an immediate manner, until laws are altered.

There is a need for long-term structural improvements that can only be mobilized through the government and 
top health care administrators, at both the national and provincial level, including the Healthcare Ministry, the PMDC and the PNC and the Punjab Healthcare Commission. It is recommended that: (i) a formal system to track errors is established to monitor and mitigate error making in the public sector of the region, with zerotolerance for non-reporting and installation of formal error tracking systems, which can be adopted from magnet hospitals in developed countries, and (ii) an increase in budget allocations are made for staffing and resource adequacy. Lastly, medical laws at the state level should be passed with specific attention to (i) penalization of medical and nurse practitioners in the event of ethical violation and (ii) protecting medical and nurse practitioners against wrongful claims by patients.

\section{Appendix}

Table 9 Information provided to nurse respondents about errors that may occur in the healthcare setup during service delivery by healthcare providers

\begin{tabular}{ll}
\hline Type of error & Example \\
\hline 1. Lack of attentiveness & $\begin{array}{l}\text { Nurse did not check wound drains or } \\
\text { dressing after surgery }\end{array}$ \\
2. Lack of fiduciary concern & $\begin{array}{l}\text { Nurse knowledge that doctor is } \\
\text { misdiagnosing and failure to question } \\
\text { this to prevent patient harm } \\
\text { 3. Inappropriate judgment }\end{array}$ \\
$\begin{array}{l}\text { Lack of skill or knowledge or incorrect } \\
\text { application }\end{array}$ \\
5. Medication error & $\begin{array}{l}\text { Administration of the wrong drug, drug } \\
\text { amount or dose of drug to patient }\end{array}$ \\
patients behalf & $\begin{array}{l}\text { Failure to provide for patient needs for } \\
\text { example advice on mother's nutritional } \\
\text { needs post delivery }\end{array}$ \\
6. Lack of prevention & $\begin{array}{l}\text { Failure to prevent harm to patient for } \\
\text { example in terms of hygiene and } \\
\text { infection }\end{array}$ \\
7. Mistaken doctor orders & $\begin{array}{l}\text { Missing or mistaking an order and as a } \\
\text { result causing patient harm }\end{array}$ \\
8. Documentation errors & $\begin{array}{l}\text { Error in making a chart entry or failure } \\
\text { to make a relevant entry all together }\end{array}$ \\
\hline
\end{tabular}

\section{Competing interests}

The authors declare that they have no competing interests.

\section{Authors' contributions}

SRJ designed the study and was responsible for data collection and analysis. RZ and MZZ supervised the conduction of the study. RZ, MZZ and FF contributed to the interpretation of data. SRJ drafted the manuscript. RZ, MZZ and FF revised it critically. All authors approved the published version.

\section{Acknowledgements}

We acknowledge support of the publication fee by Deutsche Forschungsgemeinschaft and the Open Access Publication Funds of Bielefeld University.

\section{Author details}

'Institute of Social and Cultural Studies, Sociology Department, University of the Punjab, Lahore, Pakistan. ${ }^{2}$ Institute of Social and Cultural Studies, University of the Punjab, New Campus, University of the Punjab, Lahore, Pakistan. ${ }^{3}$ Institute of Social and Cultural Studies, Faculty of Behavioral and Social Sciences, New Campus, University of the Punjab, Lahore, Pakistan. ${ }^{4}$ Department of Public Health Medicine, School of Public Health, Bielefeld University, P.O. Box 10013133501 Bielefeld, Germany.

Received: 3 July 2015 Accepted: 23 December 2015

Published online: 05 January 2016

\section{References}

1. Polisena J, Jutai J, Chreyh R. A proposed framework to improve the safety of medical devices in a Canadian hospital context. Med Devices. 2014;7:139.

2. Williams MV. Improving patient safety in radiotherapy by learning from near misses, incidents and errors. British J Radiol. 2014;80(953):297-301.

3. Williams ES, Manwell LB, Konrad TR, Linzer M. The relationship of organizational culture, stress, satisfaction, and burnout with physicianreported error and suboptimal patient care: results from the MEMO study. Health Care Manag Rev. 2007;32(3):203-12.

4. Stock GN, McFadden KL, Gowen III CR. Organizational culture, knowledge management, and patient safety in US hospitals. Qual Manage J. 2010;17(2):7.

5. Evans SM, Berry J, Smith B, Esterman A, Selim P, O'Shaughnessy J, et al. Attitudes and barriers to incident reporting: a collaborative hospital study. Qual Saf Health Care. 2006;15(1):39-43.

6. Wang S, Liu Y, Wang L. Nurse burnout: personal and environmental factors as predictors. Int J Nurs Pract. 2015;21(1):78-86.

7. Prezerakos P, Galanis P, Moisoglou I. The work environment of haemodialysis nurses and its impact on patients' outcomes. Int J Nurs Pract. 2015;21(2):132-40.

8. Kwak C, Chung BY, Xu Y, Eun-Jung C. Relationship of job satisfaction with perceived organizational support and quality of care among south Korean nurses: a questionnaire survey. Int J Nurs Stud. 2010;47(10):1292-8.

9. Aiken LH, Sermeus W, Van den Heede K, Sloane DM, Busse R, McKee M, et al. Patient safety, satisfaction, and quality of hospital care: cross sectional surveys of nurses and patients in 12 countries in Europe and the United States. BMJ. 2012;344, e1717.

10. Sorra JS, Dyer N. Multilevel psychometric properties of the AHRQ hospital survey on patient safety culture. BMC Health Serv Res. 2010;10(1):199.

11. Organization WH. Health statistics and health information systems: World Health Organization; 2012

12. Ali RM, Wajidi FA. Factors influencing job satisfaction in Public Healthcare Sector of Pakistan. GJMBR-A: Administration and Management. 2013;13(8): 61-66.

13. Khowaja K, Merchant RJ, Hirani D. Registered nurses perception of work satisfaction at a Tertiary Care University Hospital. J Nurs Manag. 2005;13(1): 32-9.

14. Khowaja K. Healthcare systems and care delivery in Pakistan. J Nurs Adm. 2009;39(6):263-5.

15. Zafar W, Siddiqui E, Ejaz K, Shehzad MU, Khan UR, Jamali S, et al. Health care personnel and workplace violence in the emergency departments of a volatile metropolis: results from Karachi, Pakistan. J Emerg Med. 2013;45(5): $761-72$.

16. Shahzad A, Malik R. Workplace violence: an extensive issue for nurses in Pakistan: a qualitative investigation. J Interpers Violence. 2014;0886260513516005.

17. Fooladi MM. Gender influence on nursing education and practice at Aga Khan university school of nursing in Karachi, Pakistan. Nurse Educ Pract. 2008;8(4):231-8.

18. Riaz H. Public health failings behind Pakistan's measles surge. Lancet. 2013; 381(9862):189.

19. Malik MR, Alam AY, Mir AS, Malik GM, Abbas SM. Attitudes and perceived barriers of tertiary level health professionals towards incident reporting in Pakistan. $N$ Am J Med Sci. 2010;2(2):100.

20. Shamim MS, Shamim MS. Medical ethics: a slow but sustained revolution in Pakistan's healthcare. J Pak Med Assoc. 2010;60(9):706.

21. Aarons GA, Hurlburt M, Horwitz SM. Advancing a conceptual model of evidencebased practice implementation in public service sectors. Adm Policy Ment Health Ment Health Serv Res. 2011;38(1):4-23.

22. Rizvi Jafree $S$. Zakar R. Gender segregation as a benefit-a qualitative study from Pakistan. Journal of Nursing Management: Zakar MZ; 2014. 
23. Jafree SR, Zakar R, Fischer F, Zakar MZ. Ethical violations in the clinical setting: the hidden curriculum learning experience of Pakistani nurses. BMC Med Ethics. 2015;16(1):16.

24. Pakistan Institute of Medical Sciences (PIMS) [Retrieved July 29'th 2013, from http://www.pims.gov.pk/. Accesed date June 26, 2015.

25. Ying L, Kunaviktikul W, Tonmukayakal $O$. Nursing competency and organizational climate as perceived by staff nurses in a Chinese university hospital. Nurs Health Sci. 2007;9(3):221-7.

26. Lake ET. Development of the practice environment scale of the nursing work index. Res Nurs Health. 2002;25(3):176-88.

27. Sorra J, Famolaro T, Dyer N, Khanna K, Nelson D. Hospital survey on patient safety culture: 2011 user comparative database report: Agency for Healthcare Research and Quality. 2011.

28. Lake ET. The nursing practice environment measurement and evidence. Med Care Res Rev. 2007;64(2 Suppl):104S-22.

29. Weston MJ. Validity of instruments for measuring autonomy and control over nursing practice. J Nurs Scholarsh. 2009;41(1):87-94.

30. Bussone K, Belknap S. Leading a strategic planning effort from the American Hospital Association. Health Research and Educational Trust, and the Institute for Safe Medication Practices. Chicago; 2002.

31. Gorini A, Miglioretti M, Pravettoni G. A new perspective on blame culture: an experimental study. J Eval Clin Pract. 2012;18(3):671-5.

32. Haw CM, Dickens $G$, Stubbs J. A review of medication administration errors reported in a large psychiatric hospital in the United Kingdom. Psychiatr Serv. 2014

33. Pham JC, Story JL, Hicks RW, Shore AD, Morlock LL, Cheung DS, et al. National study on the frequency, types, causes, and consequences of voluntarily reported emergency department medication errors. J Emerg Med. 2011;40(5):485-92.

34. Benner P, Malloch K, Sheets V, Bitz K, Emrich L, Thomas MB, et al. TERCAP: creating a national database on nursing errors. Harvard Health Policy Rev. 2006;7(1):48-63.

35. Terwee CB, Bot SD, de Boer MR, van der Windt DA, Knol DL, Dekker J, et al. Quality criteria were proposed for measurement properties of health status questionnaires. J Clin Epidemiol. 2007;60(1):34-42.

36. Cho E, Choi M, Kim E-Y, Yoo IY, Lee N-J. Construct validity and reliability of the Korean version of the practice environment scale of nursing work index for Korean nurses. J Korean Acad Nurs. 2011;41(3):325-32.

37. Van Bogaert P, Clarke S, Vermeyen K, Meulemans H, Van de Heyning P. Practice environments and their associations with nurse-reported outcomes in Belgian hospitals: Development and preliminary validation of a Dutch adaptation of the Revised Nursing Work Index. Int J Nurs Stud. 2009;46(1):55-65.

38. Parker D, Tuckett A, Eley R, Hegney D. Construct validity and reliability of the Practice Environment Scale of the Nursing Work Index for Queensland nurses. Int J Nurs Pract. 2010;16(4):352-8.

39. Chiang HY, Lin SY. Psychometric testing of the Chinese version of nursing practice environment scale. J Clin Nurs. 2009;18(6):919-29.

40. Amaral AFS, Ferreira PL, Lake E. Validation of the Practice Environment Scale of the Nursing Work Index (PES-NWI) for the Portuguese nurse population. International J Caring Sci. 2012;5(3):280-8.

41. Warshawsky NE, Havens DS. Global use of the practice environment scale of the nursing work index. Nurs Res. 2011;60(1):17.

42. Heinen MM, van Achterberg T, Schwendimann R, Zander B, Matthews A, Kózka $M$, et al. Nurses' intention to leave their profession: a cross sectional observational study in 10 European countries. Int J Nurs Stud. 2013;50(2):174-84.

43. Patrician PA, Shang J, Lake ET. Organizational determinants of work outcomes and quality care ratings among Army Medical Department registered nurses. Res Nurs Health. 2010;33(2):99-110

44. Klopper HC, Coetzee SK, Pretorius R, Bester P. Practice environment, job satisfaction and burnout of critical care nurses in South Africa. J Nurs Manag. 2012;20(5):685-95.

45. Liu K, You LM, Chen SX, Hao YT, Zhu XW, Zhang LF, et al. The relationship between hospital work environment and nurse outcomes in Guangdong, China: a nurse questionnaire survey. J Clin Nurs. 2012;21(9-10):1476-85.

46. Tei-Tominaga M, Sato F. Effect of nurses' work environment on patient satisfaction: A cross-sectional study of four hospitals in Japan. Jpn J Nurs Sci. 2015.

47. Hanrahan NP, Kumar A, Aiken LH. Adverse events associated with organizational factors of general hospital inpatient psychiatric care environments. Psychiatr Serv. 2010;61(6):569-74.
48. Lucero RJ, Lake ET, Aiken LH. Nursing care quality and adverse events in US hospitals. J Clin Nurs. 2010;19(15-16):2185-95.

49. Nantsupawat A, Srisuphan W, Kunaviktikul W, Wichaikhum OA, Aungsuroch Y, Aiken LH. Impact of nurse work environment and staffing on hospital nurse and quality of care in Thailand. J Nurs Scholarsh. 2011;43(4):426-32.

50. Hussain I. Problems of working women in Karachi. Pakistan: Cambridge Scholars Publishing; 2009.

51. Drost EA. Validity and reliability in social science research. Educ Res Perspect. 2011:38(1):105.

52. Patrick DL, Burke LB, Gwaltney CJ, Leidy NK, Martin ML, Molsen E, et al. Content validity - establishing and reporting the evidence in newly developed patientreported outcomes (PRO) instruments for medical product evaluation: ISPOR PRO good research practices task force report: part 1-eliciting concepts for a new PRO instrument. Value Health. 2011;14(8):967-77.

53. Ahmed B, Shad I, Mumtaz R, Tanveer Z. Organizational ethics and job satisfaction: Evidence from Pakistan. Afr J Bus Manage. 2012;6(8):2966-73.

54. Gadit A, Mugford G. A pilot study of bullying and harassment among medical professionals in Pakistan, focussing on psychiatry: need for a medical ombudsman. J Med Ethics. 2008;34(6):463-6.

55. Shiwani MH, Gadit A. Medical negligence: a growing problem in Pakistan. J Pak Med Assoc. 2011;61(6):610-1.

56. Pappas G, Ghaffar A, Masud T, Hyder A, Siddiai S. Governance and Health Sector Development: a case study of Pakistan. Internet J World Health Societal Politics. 2009;7:1.

57. Ahmed J, Shaikh BT. An all time low budget for healthcare in Pakistan. J Coll Physicians Surg Pak. 2008;18(6):388.

58. Ivković M. International nurse migrations: Global trends. J Geogr Inst Jovan Cvijic. 2011;61(2):53-67.

59. Naylor MD, Kurtzman ET. The role of nurse practitioners in reinventing primary care. Health Aff. 2010;29(5):893-9.

60. Khowaja K, Nizar R, Merchant RJ, Dias J, Bustamante-Gavino I, Malik A. A systematic approach of tracking and reporting medication errors at a tertiary care university hospital, Karachi. Pakistan Ther Clin Risk Manag. 2008:4(4):673.

61. Rukanuddin R. Introduction and development of NCP using ICNP ${ }^{\circledR}$ in Pakistan. Int Nurs Rev. 2005:52(4):294-303.

62. Farsi Z, Dehghan-Nayeri N, Negarandeh R, Broomand S. Nursing profession in Iran: an overview of opportunities and challenges. Jpn J Nurs Sci. 2010; $7(1): 9-18$

63. Zakar R, Zakar MZ, Mikolajczyk R, Krämer A. Intimate partner violence and its association with women's reproductive health in Pakistan. Int J Gynecol Obstet. 2012;117(1):10-4

64. Aiken LH, Clarke SP, Sloane DM, Lake ET, Cheney T. Effects of hospital care environment on patient mortality and nurse outcomes. J Nurs Adm. 2008;38(5):223.

65. Poghosyan L, Clarke SP, Finlayson M, Aiken LH. Nurse burnout and quality of care: cross-national investigation in six countries. Res Nurs Health. 2010; 33(4):288

66. Chard R. How perioperative nurses define, attribute causes of, and react to intraoperative nursing errors. AORN J. 2010;91(1):132-45.

67. Greenhalgh T, Stones R. Theorising big IT programmes in healthcare: strong structuration theory meets actor-network theory. Soc Sci Med. 2010;70(9): 1285-94.

68. Ulrich CM, Taylor C, Soeken K, O'Donnell P, Farrar A, Danis M, et al. Everyday ethics: ethical issues and stress in nursing practice. J Adv Nurs. 2010;66(11): $2510-9$

\section{Submit your next manuscript to BioMed Central} and we will help you at every step:

- We accept pre-submission inquiries

- Our selector tool helps you to find the most relevant journal

- We provide round the clock customer support

- Convenient online submission

- Thorough peer review

- Inclusion in PubMed and all major indexing services

- Maximum visibility for your research

Submit your manuscript at www.biomedcentral.com/submit 